\title{
Acesso às publicações eletrônicas e seu impacto na biblioteca
}

\author{
Access to eletronic publications and its impact on libraries
}

Eliana Coutinho

Mestre em Ciência da Informação, Fundação Oswaldo Cruz/ICICT, Rio de Janeiro, RJ

E-mail: coutinho@icict.fiocruz.br

Rejane Machado

Mestre em Saúde Pública, Fundação Oswaldo Cruz/ICICT, Rio de Janeiro, RJ

E-mail: rejane@icict.fiocruz.br

\section{Resumo}

Este trabalho tem como premissa caracterizar a coexistência, no mesmo domínio, de dois formatos (eletrônico e impresso) de periódicos científicos correntes da Biblioteca de Ciências Biomédicas da FIOCRUZ, analisando o uso desses periódicos no período de 2009 e 2010. Além de conhecer as questões que perpassam pelo processo de aquisição e os formatos dos periódicos da Biblioteca, procurou-se identificar as políticas dos editores em relação ao conteúdo do material, ao período permitido de acesso às coleções eletrônicas e ao direito de acesso e preservação digital. Como conclusão, apresentam-se algumas considerações em relação à manutenção das coleções das bibliotecas tendo em vista o crescente aumento dos periódicos eletrônicos.

Palavras-chave: Periódico eletrônico; Assinatura de periódico; Acesso online; Preservação digital de repositório informacional.

\begin{abstract}
This work aims to characterize the coexistence of two formats (print and electronic) at the same area of current scientific journals in the FIOCRUZ Library of Biomedical Sciences, analyzing the use of these journals over the period 2009 to 2010. Besides knowing issues that underlies the acquisition process and the formats of the library's journals, we attempted to identify editors' policies concerning to the material contents, the allowed access period to online collections and the right of access and digital preservation. In conclusion we present some considerations regarding to the maintenance of libraries' collections considering the growing number of electronic journals.
\end{abstract}

Key-words: Electronic journal; Journal subscription; Online access; Digital preservation of informational repository

\section{Introdução}

Os primeiros periódicos científicos surgiram em meados do século XVII com a publicação de Jounal des Sçavans em Paris e Philosophical Transactions of the Royal Society of London em Londres, representando um marco histórico na comunicação científica. Embora tenham sido criadas com conteúdos e intenções diferentes (MEADOWS, 1999), estas publicações

InCID: R. Ci. Inf. e Doc., Ribeirão Preto, v. 2, n. 2, p. 178-188, jul./dez. 2011. 
utilizadas para o registro dos achados dos cientistas em formato impresso, potencializando a possibilidade de divulgação científica.

Na última década do século XX, com as novas tecnologias de informação e comunicação, iniciou-se um novo modo de divulgação dos achados dos cientistas, que de certa forma coadunava-se com o anseio da comunidade de acessar os conteúdos dessas publicações de forma mais rápida, surgindo então o periódico eletrônico. Esse novo formato se desenvolveu em etapas. Inicialmente o texto impresso e o eletrônico eram iguais e mais tarde houve um acoplamento de ferramentas de busca e serviços de alerta no periódico eletrônico, gerando modificações no modo de produção desse novo formato.

Nos dias atuais, o formato eletrônico de publicação científica se tornou obrigatório e generalizado por apresentar uma relação de custo/benefício mais favorável quando comparada à versão impressa. Além disso, mais rapidez na produção, distribuição e acesso. O que se caracteriza como desvantagem do novo formato é o custo dos equipamentos e as questões de conexão e a velocidade de acesso, bem como, às políticas, normas e procedimentos de disponibilização.

Este trabalho tem como premissa caracterizar a coexistência no mesmo domínio espaço/temporal dos periódicos científicos nos dois formatos - eletrônico e impresso a partir da coleção de periódicos correntes da Biblioteca de Ciências Biomédicas da FIOCRUZ. Para construção da realidade efetuou-se a análise desses periódicos em relação ao tempo de existência do título, ao uso da coleção, à forma de aquisição e aos formatos disponíveis.

A partir do levantamento de fontes documentais foram identificados os periódicos assinados pela Biblioteca e a sua disponibilização nos portais de informação e sites de editores, com vistas a identificar políticas referentes ao acesso e preservação do formato eletrônico.

\section{Cenário dos periódicos no período 2009 - 2010 quanto à aquisição e formato}

O primeiro passo foi conhecer as questões que perpassam pelo processo de aquisição dos periódicos da Biblioteca. Para tal, foi necessário traçar o cenário atual do repositório da biblioteca tendo por base o ano de 2009, agregando os títulos comprados, doados e permutados a partir do 
registro de recebimento dos fascículos no sistema. O total de periódicos adquiridos no ano foi de 945 títulos através dos três tipos de aquisição: compra, doação e permuta. Identificou-se 330 títulos disponíveis nos formatos online e impresso, 5 somente no formato online, e 610 disponíveis no formato impresso.

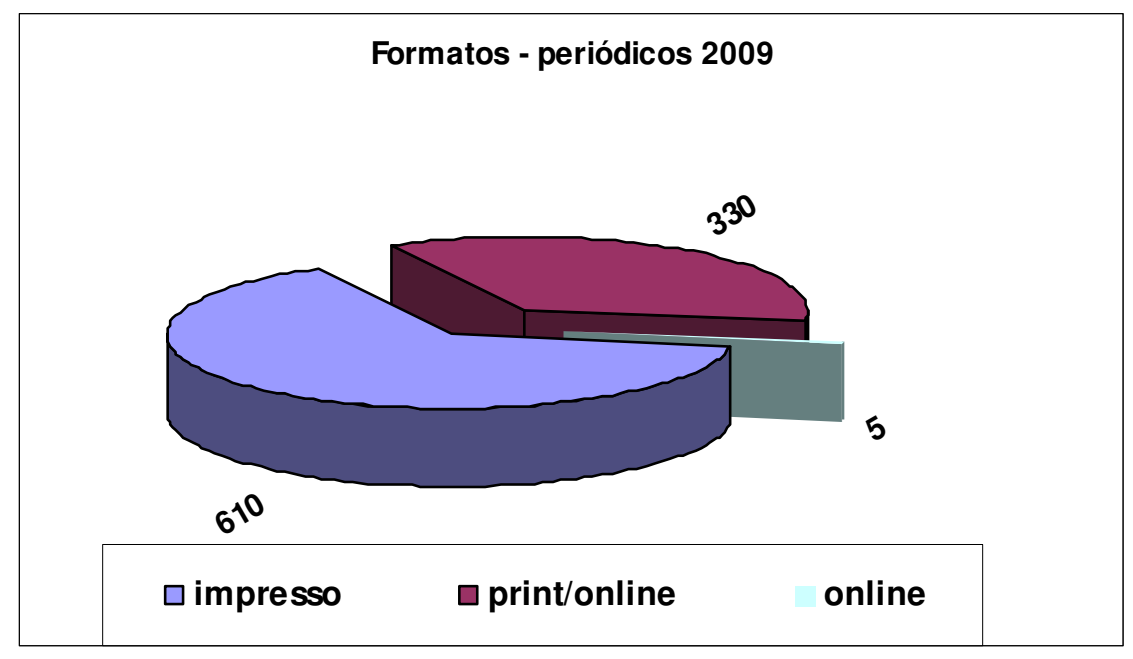

Para análise comparativa, foram incluídos os títulos que chegaram à Biblioteca em 2009, inclusive os que constavam como novos, mas que, no caso das doações e permuta, eram apenas mudanças de título e não novos. Desse modo foram acrescentados só os títulos novos, formando um total de 916 títulos, o que representa um crescimento do acervo.

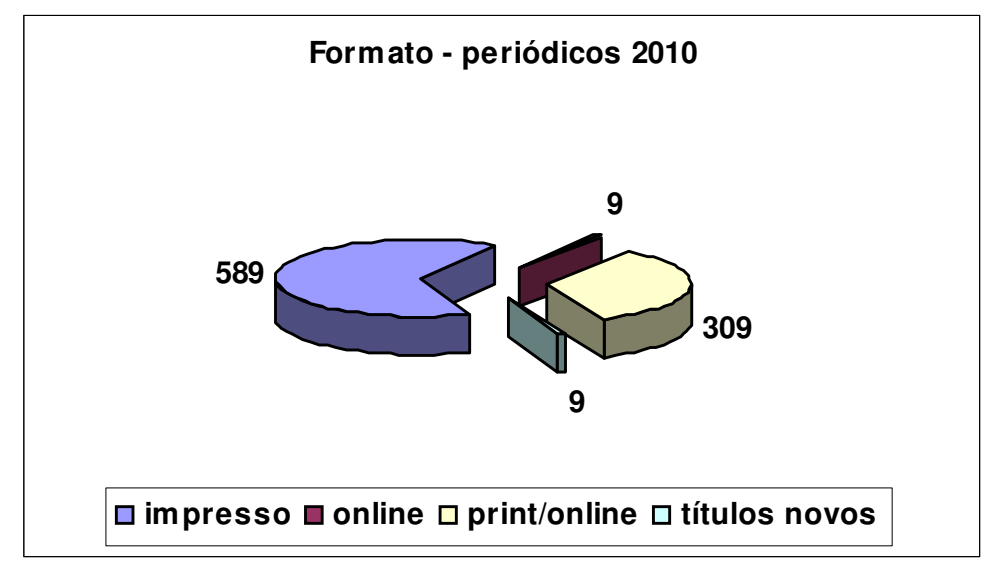

Na análise conjunta dos anos de 2009 e 2010 constatou-se que, em relação à forma de aquisição, houve diminuição de $14 \%$ dos títulos adquiridos por meio de doação. O mesmo ocorreu com os títulos recebidos através de permuta com as Memórias do Instituto Oswaldo Cruz, que apresentou um decréscimo de 9\%, provavelmente devido aos seguintes motivos: encerramento do título, publicação de fascículos com atraso ou suspensão da remessa pelo editor 
e, consequentemente, cancelamento do intercâmbio. Os títulos adquiridos por compra, apesar da inclusão em 2010 de nove títulos novos, esta forma de aquisição apresentou um pequeno aumento de $(0,31 \%)$, certamente devido ao cancelamento das assinaturas de títulos com baixo índice de utilização, compensado pelo acréscimo dos títulos novos.

Para este trabalho, optou-se por usar os dados referentes a periódicos adquiridos por compra devido ao seu alto custo e grande número de títulos. A política de aquisição da Biblioteca é comprar apenas periódicos na forma impressa. No ano de 2009 foram comprados 634 títulos, dos quais 482, somente na forma impressa, um título publicado somente no formato eletrônico, pois que só existe nesse formato, e 151 títulos cujos editores disponibilizam o acesso online como parte da assinatura do formato impresso. Em 2010, foram comprados 636 títulos, dos quais 473 na forma impressa, três somente no formato eletrônico e 160 nos dois formatos.

Em relação ao formato, comparando os títulos adquiridos em 2010, observou-se aumento no número de títulos com acesso somente online, o que confirma a tendência dos editores em disponibilizar cada vez mais seus periódicos apenas na Internet em detrimento da distribuição do formato impresso. Este dado é referendado quando se verifica que o número de títulos com acesso somente na forma impressa em 2010 diminuiu 1,8\% em relação a 2009, o que quer dizer que alguns títulos passaram a ter acesso nos dois formatos (print+online) ou mesmo somente no formato eletrônico (online).

\section{Estudos de uso dos periódicos}

Segundo Bégault (2009), o periódico, desde a sua criação como uma forma de comunicação científica alternativa ao livro, assumiu com o passar dos séculos, o papel de um meio de divulgação científica e de detentor da propriedade intelectual, facilitador ainda da avaliação entre pesquisadores.

A partir do incremento da Internet na década de 90, o periódico, antes impresso, começa a aparecer também no formato eletrônico, como uma alternativa ao meio tradicional de divulgação científica nas diversas áreas do conhecimento. Esta dualidade de formato tem conotações diferentes de acordo com a área. Tenopir (2005), em seus estudos, identifica que o formato 
impresso é o mais lido na área médica, ao passo que nas outras áreas científicas a publicação eletrônica corresponde a 2/3 do material lido.

O estudo de uso dos periódicos da Biblioteca de Ciência Biomédicas teve como base os dados do período de 2009 a outubro de 2010. As estatísticas relativas à utilização dos fascículos impressos foram obtidas através de relatórios gerados pelo software Aleph, utilizado para o gerenciamento da Biblioteca. Como não foram obtidos dados referentes aos acessos online, trabalhamos apenas com os dados de acesso à publicação impressa. Foram elaboradas planilhas Excel com os dados de uso em 2009: título, formato e o número de vezes em que foi utilizado resultando um ranking para os 583 títulos em 2009. Foram destacados 26 títulos com índice de uso entre 50 a 251 considerados os mais consultados no ano, com total de 2.301 vezes de uso. A seguir foram identificados 91 títulos consultados entre 20 e 49 vezes de uso e os 466 títulos restantes ficaram abaixo de 20 vezes de uso.

Dentre os 26 títulos mais consultados, 19 constam como disponíveis apenas no formato impresso e 7 títulos disponíveis também nos dois formatos - impresso e online. Cada um dos títulos foi pesquisado no Portal CAPES através dos endereços de Internet Protocol (IP) da FIOCRUZ, a fim de identificar a disponibilidade de acesso eletrônico. Verificou-se que três desses títulos não estão disponíveis no portal e recebem mais de 100 consultas na biblioteca (251, 191 e 110) e estão disponíveis para os usuários apenas no formato impresso. Outros três títulos adquiridos somente no formato impresso receberam também mais de 100 consultas, ou seja, (117, 118, 123 vezes), mas nesse caso os três títulos estão disponíveis na forma eletrônica pelo Portal CAPES. No que tange às áreas mais consultadas, observou-se que esses seis títulos com número de consultas maior do que 100 vezes, três são de medicina veterinária, um de doenças infecciosas, um de química médica e um de farmácia, todos com foco nos avanços da área biomédica. Verificou-se que dos 26 títulos mais consultados na Biblioteca, 20 receberam consultas no mesmo período entre 50 e 100 vezes. Destes 20, 4 estão disponíveis nos formato impresso e online e 16 estão disponíveis somente no formato impresso. Em relação ao acesso eletrônico, observou-se que somente 4 não estão disponíveis nos portais de informação.

Com o objetivo de verificar se esses 26 títulos vêm sendo muito consultados há mais tempo, foram identificados primeiramente pela história do periódico que tiveram mudanças de títulos. Assim aos 26 títulos foram acrescentados aqueles 13 títulos anteriores, formando um total 
de 39 títulos para essa análise. Efetuou-se busca na base de dados, no módulo de circulação do sistema Aleph, para verificar o número de vezes em que esses itens foram utilizados. O uso é registrado através de leitura do código de barras existente em todos os fascículos dos periódicos. Esta forma de controle de uso foi implantada na biblioteca a partir de 2002. Logo, a pesquisa de uso através da base de dados iniciou-se em 2002 e continua até 2010. O quadro abaixo compara o uso em 2009 e no período anterior:

Títulos mais usados - n de vezes
\begin{tabular}{|c|c|}
\hline 2009 & 2002 a 2010 \\
\hline 2.301 & 12.667 \\
\hline
\end{tabular}

A partir dos 39 títulos elaborou-se uma seleção considerando somente os que estão disponíveis na Internet com texto completo, resultando em 18 títulos. No momento do estudo, seis têm texto completo sem restrição de acesso, quatro o texto completo é acessado via endereço de IP da FIOCRUZ, dois estão disponíveis no Portal CAPES e seis têm os resumos e alguns textos completos disponíveis. Constatou-se que apesar do processo de compra da biblioteca incluir somente a forma impressa dos periódicos alguns podem ser acessados via online, pelo portal CAPES ou por bases de dados adquiridas pela FIOCRUZ.

\section{Política dos editores em relação ao acesso online dos periódicos técnico-cientificos}

Além das pesquisas nos periódicos da Biblioteca de Ciências Biomédicas, efetuou-se busca de informação sobre os acessos eletrônicos nos sites dos editores para compreender a forma como os periódicos estão disponibilizados na Internet, dos 636 títulos assinados pela Biblioteca de Ciências Biomédicas para o ano de 2010 cujo resultado se segue:

Acesso

- 232 títulos pelo Portal CAPES, (36\% do total de títulos assinados);

- 154 títulos têm acesso através do endereço IP da FIOCRUZ, cujas assinaturas são no formato impresso e acesso online gratuito (24\% do total de assinaturas);

- 215 títulos têm acesso sem identificação do usuário, (33\% do total de títulos assinados). 
- 19 títulos são obras de referência adquiridas pela biblioteca no formato impresso sendo a publicação impressa a única fonte de pesquisa atual da Biblioteca.

- Apenas 4 títulos não possuem sites, tendo sua pesquisa restrita ao formato impresso, $(0,6$ $\%$ do total de títulos assinados) ; 3 títulos possuem sites, porém não disponibilizam informações sobre o material publicado.

Conteúdo do material online:

- 516 títulos permitem o acesso ao tex to completo (81\% dos títulos assinados);

- 85 títulos permitem acesso somente aos resumos dos artigos (13\% dos títulos assinados);

- 21 títulos permitem acessos aos resumos e apenas a alguns dos textos completos (3\% dos títulos assinados);

- 7 títulos permitem acesso somente ao sumário dos fascículos (1\% do total de títulos assinados);

- 1 título exibe somente os índices alfabéticos (autores, títulos);

Período de tempo de disponibilidade das coleções

A pesquisa revelou coleções de periódicos disponíveis na Internet relativo aos anos 1840 até 2010, com textos completos e resumos dos artigos ou exibindo simplesmente os sumários dos fascículos. No entanto, 276 deles disponibilizam artigos com texto completo somente a partir da década de 90, tendo o período de 1995 a 1997 concentrando o maior número de títulos, conforme quadro abaixo:

Textos completos disponíveis

\begin{tabular}{|c|c|}
\hline texto completo & 1995 a 1997 \\
\hline 516 & 223 \\
\hline
\end{tabular}

O que representa $43 \%$ dos 516 títulos disponíveis em texto completo, ou 35\% do total de 636 periódicos assinados. Esta concentração talvez se deva ao fato de que durante a década o crescimento da Internet representou mais de $100 \%$ ao ano, um período de crescimento explosivo principalmente em 1996 e 1997 conforme análise de Coffman e Odlyzko (2010). A concentração acima evidenciada é decorrente do surgimento do primeiro arquivo eletrônico pelos preprints em InCID: R. Ci. Inf. e Doc., Ribeirão Preto, v. 2, n. 2, p. 178-188, jul./dez. 2011. 
1991. Os preprints são uma forma de publicar os achados de forma diferenciada, libertando-se das amarras dos grandes editores. Este marco, na década de 90 acionou mecanismos de mudança no ciclo da informação.

Por outro lado, 216 periódicos disponíveis em textos completos sem restrição representam $34 \%$ do total de periódicos assinados, enquanto que outros 24 títulos permitem o acesso a apenas alguns dos artigos em texto completo, independentemente do período de publicação.

Em geral, as editoras, apesar de ainda manterem o formato impresso, estão utilizando fortemente a mídia eletrônica na divulgação de seus periódicos. A política de disponibilização e manutenção das coleções na Internet é bastante variada, ou seja, alguns títulos são disponibilizados desde o início da sua publicação, ao passo que outros têm o acesso eletrônico restrito a períodos determinados. No caso do acesso por endereço de IP; o acesso se dá somente durante a vigência da assinatura, podendo o assinante, no entanto, obter a propriedade do material, tal qual na forma impressa, desde que a biblioteca se proponha a armazenar a coleção eletrônica em servidor específico da instituição, com tecnologia própria e recursos humanos capacitados para a manutenção. Existe outra opção que é oferecida pelos editores no qual o serviço de guarda das coleções exige pagamento de uma taxa de manutenção anual, que deve ser previsto pela instituição além dos gastos com as assinaturas.

\section{Direito de acesso e preservação do formato eletrônico}

Realizou-se pesquisa nos sites dos editores com substancial número de títulos assinados pela biblioteca (413 títulos) para identificar as respectivas políticas de direito de uso. As regras referentes aos direitos dos assinantes não são claras com relação ao acesso após cancelamento de assinatura. Os editores dispõem de termo de acordo de uso, no qual o assinante está sujeito a cláusulas que comprometem a preservação das coleções na forma eletrônica. Consta que os acordos podem ser alterados a qualquer momento pelo editor com inclusão de novas cláusulas que podem ter restrições ou novas obrigações para o assinante, colocando-o em situação de submissão às regras impostas pelo editor.

Para referendar essas informações solicitou-se via e-mail aos três maiores editores informações sobre os acessos, em caso de cancelamento de assinatura. Dois editores InCID: R. Ci. Inf. e Doc., Ribeirão Preto, v. 2, n. 2, p. 178-188, jul./dez. 2011. 
responderam: um informou que o acesso online se mantém ativo durante os anos previamente pagos, porém sem permissão ao material corrente; outro informou que no caso da assinatura print+online, permite acesso somente para o ano corrente e, se a assinatura for suspensa o acesso ao material retrospectivo terá que ser pago. Tendo em vista que as bibliotecas têm sido repositórios por excelência de coleções físicas disponíveis para consultas em qualquer tempo, os resultados deste estudo indicam que no caso da preservação digital, existem várias questões que precisam ser avaliadas.

\section{Conclusão}

O periódico eletrônico vem apresentado forte tendência mundial de desenvolvimento por apresentar vantagens em relação às facilidades de acesso e atualização. No entanto, esta tendência desperta inquietação do ponto de vista das bibliotecas, cujos gestores devem refletir profundamente acerca das seguintes questões: as formas de preservação digital dos repositórios, a organização e o acesso aos repositórios informacionais digitais e as condições de armazenamento deste tipo de suporte informacional.

Apesar do crescimento do periódico eletrônico, o estudo de uso dos periódicos na Biblioteca de Ciências Biomédicas constatou que muitos usuários preferem efetuar suas consultas na publicação impressa ao invés de acessar os textos pela Internet, mesmo quando estes estão disponíveis.

Em relação ao conteúdo disponibilizado pelos editores, o acesso aos textos completos dos artigos é o que mais interessa aos usuários e bibliotecas. No entanto, normas e procedimentos quanto aos direitos de acesso após interrupção da assinatura não estão disponíveis nos sites dos editores ou não são claros e transferem todo e qualquer risco ao assinante.

Na Biblioteca de Ciências Biomédicas o acesso aos periódicos eletrônicos é possível, seja pela assinatura impressa, quando esta inclui a forma eletrônica, seja devido às facilidades do Portal CAPES que está disponível para a FIOCRUZ por ser uma Instituição de Ensino Superior. 
Porém, essa facilidade não pode ser considerada como um fator decisivo para a não manutenção das assinaturas de coleções na forma impressa, especialmente aquelas já existentes há muito tempo na Biblioteca, tais como 'Lancet' desde 1832 e 'JAMA' desde 1833.

É preciso salientar que não existe garantia de que o Portal CAPES tenha a mesma vida útil do acervo impresso disponível na Biblioteca. O mesmo se aplica em relação aos títulos que têm acesso livre, sem identificação do usuário, que podem a qualquer momento deixar de ser acessíveis, dependendo da política do editor.

Diante dessas constatações, cabe aos gestores das bibliotecas buscarem formas de preservação e de integração da forma impressa com as novas modalidades do processo de produção e transmissão da informação. Substituir as assinaturas impressas pelas eletrônicas é, pelo menos por enquanto, uma decisão de alto risco, pois as consultas a fascículos retrospectivos não é garantida nos sites dos editores, que podem a qualquer momento mudar as políticas de acesso. Além disto, não há garantias de continuidade de acesso quando a assinatura não é renovada, a não ser que o assinante continue pagando pelo serviço oferecido atualmente por editores de armazenamento da coleção digital em servidor específico. E o que dizer dos periódicos que tiverem sua publicação encerrada? Estes podem desaparecer do espaço virtual mesmo que a biblioteca tenha pagado suas assinaturas enquanto estavam correntes. Em contrapartida, as coleções impressas estarão sempre à disposição dos usuários nas estantes.

Portanto, as novas tecnologias que possibilitam a disponibilização e o uso de repositórios de forma mais ágil na Internet trazem à tona uma questão muito importante, que é a preservação da memória institucional. Assim sendo, é necessário estabelecer critérios para que esta memória não seja ameaçada pela substituição da forma impressa do repositório informacional pela forma eletrônica, tendência observada nos últimos anos. Conectar máquinas e conteúdos é responsabilidade de pessoas que obrigatoriamente devem estar envolvidas na preservação e no gerenciamento do uso desses repositórios.

InCID: R. Ci. Inf. e Doc., Ribeirão Preto, v. 2, n. 2, p. 178-188, jul./dez. 2011. 


\section{Referências}

BÉGAULT, B. O periódico científico, um papel para a mediação de informação entre pesquisadores: qual seu futuro no ambiente digital? RECIIS, v.3, n.3, p.91-96, 2009.

COFFMAN, K.G.; ODLYZKO, A.M. The size and growth rate of the Internet. AT\&T Labs. Disponível em: http://www.dtc.umn.edu/ odlyzko/doc/internet.size.pdf. Acesso em: 24 ago. 2010.

CAPES. O Portal Brasileiro de Informação Científica: CAPES. Disponível em: $<$ http://www.periodicos.capes.gov.br>. Acesso em: 9 nov. 2009.

ELSEVIER. Elsevier website privacy policy. Disponível em: $<$ http://www.elsevier.com/wps/find/privacypolicy_cws_home/'privacypolicy>. Acesso em: 22 nov. 2010.

MEADOWS, A.J. A comunicação científica. Brasília: Briquet de Lemos/Livros, 1999.

SPRINGER. Terms of use. Disponível em: <http://www.springer.com/generic/terms?SGWID=040112-0-0-0>. Acesso em: 22 nov. 2010.

TENOPIR, C. Discovering the magic: faculty and students use of electronic journals. Serials librarian, v.49, n.3, p.159-164, 2005.

WILEY. Terms and conditions of use. Disponível em: <http://onlinelibray.wiley.com/termsAndConditions>. Acesso em: 22 nov. 2010. 